\title{
İdeal Hizmetkarlar Olarak Görülen Hadımların Bizans Kültür-Sanat Hayatındaki Yerine İlişkin Kısa Bir Değerlendirme
}

\author{
A Brief Evaluation on the Place of Eunuchs as Ideal Services \\ in Byzantine Culture And Art
}

Feray KORUCU YAĞIZ*

$\ddot{O}_{z}$ : Hadımlar, tarih boyunca ortak bir özellik olarak birçok medeniyetin hem toplumsal hem de siyasal hayatında etkin bir rol oynamıştır. Farklı amaçlar doğrultusunda insanoğlu tarafindan var edilen bu üçüncü kimlik, 1100 yıl gibi uzun bir geçmişe sahip olan, yapısal oluşum bakımından hem Romalı hem de Anadolulu olan Bizans dünyasında da kendince bir yer edinebilmiştir. Merkezi kuvvetin kurulmasında önem arz eden ve sistem içerisinde her sahada belli bir etki oranında varlık gösteren hadımlarla ilgili dönem kaynaklarının ayrıntılı bilgi sunmadığı görülmüştür. Hadımlar ve onların yaşamına ilişkin bilgilere erişimin zor olduğu bu sahada, genel-geçer bilgi birikimine, XX. yüzyıl sonlarında, Bizans sosyal tarihine olan ilginin arttı̆ğ dönemle birlikte ulaşılmaya başlanmıştır. Öyle ki iktidarsız erillerin, siyasi anlamda imparatorluk içinde neredeyse imparator kadar iktidar ve yetki kazanmaları, sosyal anlamda belli bir statüde bulunan kişi gruplarını işaret etmeleri gibi pek çok husus, bu yüzyıl sonrasında yapılan çalışmalarla ortaya konulmaya çalışılmıştır. Bu çalışmada; erillerin iktidarsızlaştırılması meselesine tarihsel bir perspektiften bakılmış, Bizans İmparatorluğu'nda iktidarsızlaştırmanın ne zaman ve hangi yöntemler takip edilerek gerçekleştirildiğine değinilmiş, ulaşılan tasvirler üzerinden hareket edilerek hadım edilen kişilerin imparatorluğun siyasi, sosyal, dini yaşamdaki rolü ile kültür-sanat sahasındaki yeri tartışılmaya çalışılmıştır.

Anahtar sözcükler: Bizans, Sanat- Kültürel Yaşam, Cinsiyet, Hadımlar

\begin{abstract}
The eunuchs played an active role in many civilizations, both social and political life. This third identity, which created by human in the direction of different purposes, has also existed in the Byzantine culture, which has a long history of 1100 years, in terms of structural formation, both Roman and Anatolian culture. Unfortunately, the Byzantine sources did not provide enough information about the this third identity that exists in culture. The datas, which provides some details about the eunuchs and their lives started to be reached with the increase interest in the Byzantine social history since the late $20^{\text {th }}$ century. The impotent masculine almost empower in the empire, gain power and authority in the political sense as much as the emperor and pointing to groups of people with a certain social status and many issues such as this have been tried to be revealed through the studies conducted after this century. In this study; the issue of desexualization of the masculine has examined from a historical perspective, when and by which methods of desexualization of the masculine in the Byzantine Empire is addressed, based on the images has reached the role of eunuch in the political, social and religious life and the place of eunuchs in art and cultural life is discussed.
\end{abstract}

Keywords: Byzantine, Art And Cultural Life, Gender, Eunuchs

\footnotetext{
* Arş. Gör. Dr., İstanbul Medeniyet Üniversitesi, Edebiyat Fakültesi, Sanat Tarihi Bölümü, Bizans Sanatı Anabilim Dal1, İstanbul. feray.korucu@medeniyet.edu.tr, https://orcid.org/0000-0003-2208-7330
} 
İktidarın ve istikrarın, devletin hâkim olduğu tüm imkânların birincil göstergesi olarak kabul edilen saraylar, sahip oldukları ihtişamın kuvvetini, devlet içinde ve dışında katı kurallar çerçevesinde alınan tedbirlerle kurabilmiştir. Siyasetten kuvvetli olmanın içerideki ve dişarıdaki sağlamlığa bağlı olduğuna inanan saray, yerine getirdiği bu şartlarla kurumlar arası birliği sağlayabilmiş ve merkeziyetçi anlayış çerçevesinde gerçekleştirilen otoriteyi sahip olunan sınırlar üzerinde hâkim güç kılabilmiştir. İtaatte kusursuzluk kıstasına ulaşmak amacıyla yapılan, esasında sarayın kendisi özellikle kadınları ve kadınlarının etrafında bulunan adamlara olan güven duygusunun tartışılmasını gerekli kılan hadım çalışanların (Ringrose 2004, 82) varlığı ise devlet içerisinde güçlü bir sistemin kurulması için yaratılması elzem olan temel ögelerden sadece biri olarak tanımlanabilmiştir.

Bizans'ta olduğu gibi her toplumda var olan, güçlü bir sistemin kurulmasında sağlam bir temel oluşturacağına inanılan hadımların varlık ve yaşam mücadelesi, onların bu çarpıcı hayat öyküleri, en çıplak haliyle XIX. yüzyılda tartışılmaya ve konuşulmaya başlanmıştır. Gerek arkeoloji sahasında (1), gerek tıp alanında gerekse yazılı (2) ve görsel sanatlarda (3) yapılan birçok çalışmayla konu bambaşka yönleriyle irdelenmiş; hadımların yaşam biçimleri, toplum içindeki yeri, saray içindeki konumu, görev edindikleri pozisyonlar gibi çoğaltılabilecek pek çok husus, bahsi geçen araştırma sahalarında yürütülen çalışmalar vasıtayla belirlenmeye ve aydınlatılmaya çalışılmıştır.

Farklı bir cinsiyet grubu olarak sosyal yapılanmada etken rol oynayan hadımların, tarih sahnesine ilk olarak ne zaman çıktığıyla ilgili kesin bir bilgi ortaya konulamamıştır. Ancak Doğu ve Akdeniz coğrafyasında yaygın olan, hudutları aşarak Uzakdoğu'ya kadar giden hatta XVIII. yüzyıl İngiltere'sinde dâhil varlığıyla karşılaşılan (Fig. 1) uygulamanın, ilk örnekleri ve tarihiyle ilgili farklı teoriler temel alınarak birtakım yorumların ortaya konulabildiği görülmüştür. Buna göre; modern dönem araştırmacıları, uygulamanın yerleşik sisteme geçişle birlikte başladığını söylerken (burada hayvanların ehlileștirilmeye başlandığı dönem kıstas olarak kabul edilmiştir) (Taylor 2000, 10) antik dönem araştırmacıları, köklü bir gelenek gibi nesilden nesile, kültürden kültüre geçiş yapan hadım etme uygulamasının kökenlerinin farklı toplumsal kurumlarda atıldığını söylemiştir (4). Farklı araştırma sahalarında yürütülen çalışmalar ve bu çalışmalar üzerinden yürütülen yorumlar konuyla ilgili farklı bakış açılarının yakalanmasına olanak sağlamıştır. Hadımların; tarih içerisindeki varlığını belli bir sürece sabitleyen, bu süreci Mezopotamya'dan öteye götüren; hadımlarla Geç Hitit döneminde karşılaşıldığını, aynı sistemin daha sonraki dönemlerde Asurlular tarafından benimsendiğini ifade eden bazı açıklamalarla karşılaşılması da bu nedenle önemli kabul edilebilmiştir (Deller 1999, 302-310). Hadımların tarihi süreç içerisinde toplum içindeki varlığına ilişkin yazılı kaynakların yapmış olduğu tüm bu referanslar, sanat eserleri üzerinde karşılaşılan görsellerle de eşleştirilmeye ve pekiştirilmeye çalışılmıştır. Dünyanın ilk kentsel kuruluşu olan, Sümer şehri Uruk’tan (5) gelen uzun, dikdörtgen formlu, yatayda üç ayrı panele ayrılan eser üzerinde yer alan sahneler, açıklamaya çalıştığımız durum için ispat niteliği taşımıştır (Fig. 2). Öyle ki farklı konular üzerine temellenen, birbirinden bağımsız çok sayıda sahneyle süsleme kompozisyonu tamamlanan eserde, konumuz itibariyle bizler için önem arz eden esas betimin, eserin üst panelinin sağ tarafinda tasvir edildiği görülmüş̧ür. Burada lir çalan bir insan figürü ile muhtemelen bu figüre şarkılarıyla eşlik eden uzun saçl1, göğsü açıkta tasvir edilen figürün, saray görevlilerinden olan hadımlar olduğu düşünülmüştür (Kleiner 2016, 24-25).

Doğu dünyasının büyük imparatorlukları tarafından yaratılan eril bireylerin hadım edilmesi geleneği ve hadım edilen insanların saray içinde hizmet sektöründe çalışan görevli olarak vazifelendirilmesi meselesi (Tougher 2013, 280), süreklilik arz ederek Roma İmparatorluk 
Dönemi'ne de geçebilmeyi başarmıştır (Hathaway 2012, 7). Ermeni, Pers ve Kafkas (Jones 1986, 851) başta olmak üzere farklı rrk ve toplumlara mensup olan kişiler arasından seçilen hadımların (6), bu dönemde de sarayın ve asilzadelerin emrinde çalışan ideal hizmetkarlar olarak görev aldığı bilgisine erişilmiştir.

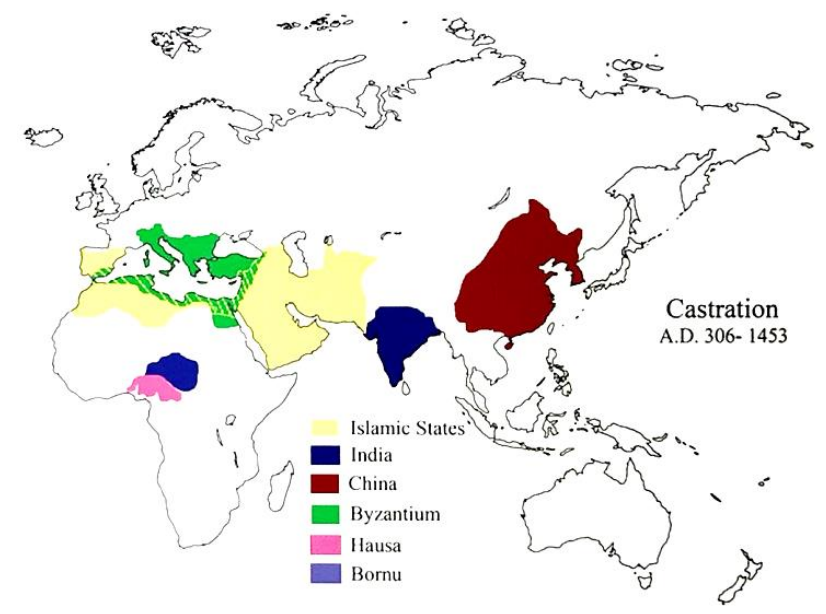

Fig. 1. IV-XV. Yüzyıla Kadar Coğrafya Olarak Hadımların Yaşadı̆̆ 1 Yeri Gösteren Harita.

Kaynak: Reusch K. 2016, 66, fig. 5.2

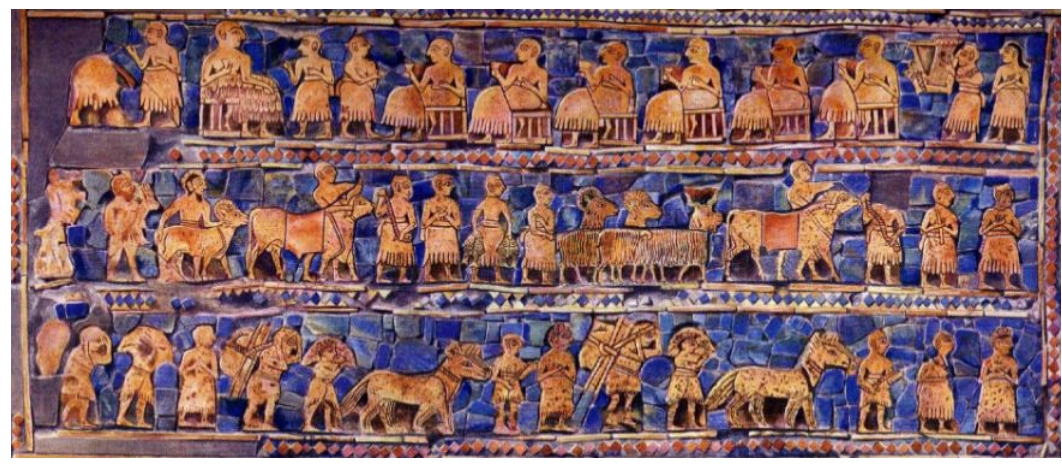

Fig. 2. Ahşap Kutu, Kraliyet Mezarlı̆̆ 779 No.'lu Mezar, MÖ 2600-2400, Ur-Irak, British Museum.

Kaynak: https://www.britishmuseum.org/collection/object/W_1928-1010-3 (29.06.2020).

Doğu kültürünün tıpkı bir miras gibi insanlık tarihine bıraktığı saraylardaki ve asilzadelerin evlerindeki hadımların varlığı, Roma İmparatorluğu'nun ikiye ayrılmasıyla imparatorluğun doğuda devam eden güçlü kolu, Bizans İmparatorluk sistemine de geçiş yapmıştır. IV. yüzyıldan itibaren devlet içinde varlık gösteren ve var edilen düzende kendilerince belli bir yer edinen hadımların sayıları, gün geçtikçe artmıştır. Özellikle VI. yüzyılda- bir önceki dönemde olduğu gibi- İmparator I. Iustinianos tarafindan konulan katı yasaklara rağmen ivme kaybetmeden devam eden köle ticaretiyle (7) farklı millet ve toplumdan gelen binlerce hadımın, imparatorluk sınırları içerisine girdiği görülmüştür. Başından beri sistemin içinde yer almayı başaran özellikle VII- XII. yüzyıllar arasında siyasi ve dini alanda oldukça etken rol oynadıkları bilinen hadımların nicelik olarak devlet içindeki bu varlıkları, antik dönem yazılı kaynaklarında "devletin başkentinde, devlet bürokrasisinde binlerce kişi çalışmaktaydl; hadımlar ise baharda hayvan sürülerinin etrafinda bulunan sinekler kadar çoktu" şeklinde geçen çarpıcı ifadelerde de tanımlanmıştır (http://www.tertullian.org/fathers/libanius_monody.htm, 2021).

Bizans İmparatorluğu'nda, hadımların devlet için taşıdığı önem, sadece ticaret konusuna açıklık getiren, bu kişilerin sayılarıyla ilgili bilgi veren metinler üzerinden yapılan bir değerlen- 
dirmeyle anlaşılır hale getirilmeye çalışılmamıştır. Dönem içinde hadım edilmiş bir kölenin imparator ya da eş değerindeki bir rütbeye verilebilecek önemli bir hediye olarak kabul görmesi gibi birtakım bilgilere ulaşılması, yapılan değerlendirmede farklı kriterlerin bir araya getirilmesini ve bu bilgilerin sentezlenmesini sağlamıştır. Örneğin "Güzel saçlarıyla hadımlar, hepsi de yakışıkll; ipekli Acem giysiler içinde ve boyunlarının etrafinda altın burma gerdanlıklar" sözleriyle tanımlanan on hadım edilmiş çocuğun İmparator Basileios'a amcası tarafından dügün hediyesi olarak verilmesi bilgisi ile (Herrin 2010, 232) döneme ait bir el yazması üzerinde Peloponnesos'tan (Mora Yarımadası) İstanbul'a seyahate giden ve şehre aralarında hadımların olduğu bilgisine de erişebildiğimiz onlarca hizmetkarının taşıdığ bir taht üzerinde giriş yapan Danelis/Danielis'in yer aldığ tasvirin (Fig. 3) irdelenmesi (Herrin 2009, 168) bahsetmeye çalıştığımız bu durum için bir kıstas yaratabilmiştir (8).

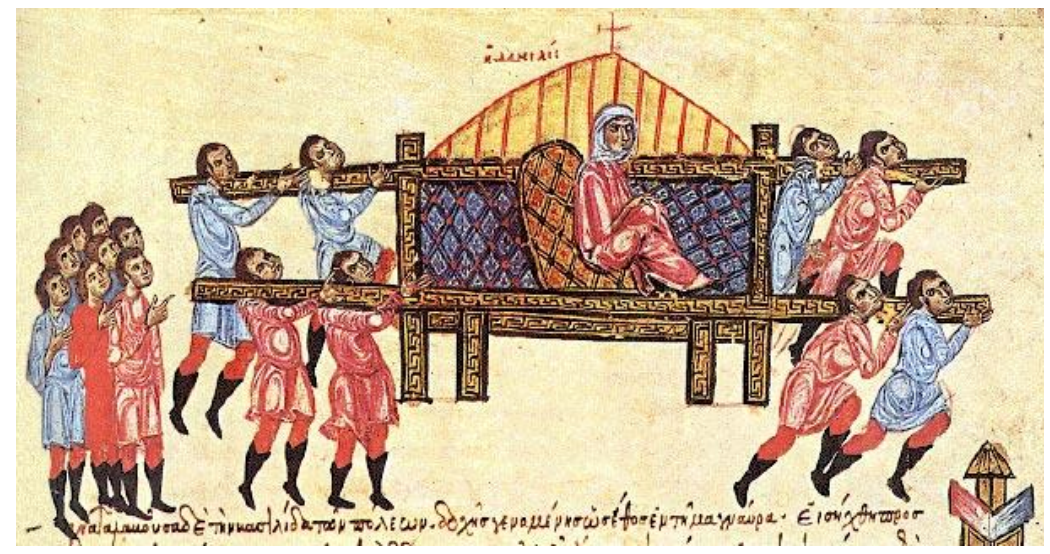

Fig. 3. Danelis'in İmparator I. Basileios'u Ziyareti (Konstantinopolis'e Hadımların Taşıdığı Bir Taht Üzerinde Oturur Şekilde Girmiştir, XII. yüzyıl.

Kaynak: Madrid Skylitzes, fol. 102r, Biblioteca Nacional Madrid. https://inpress.lib.uiowa.edu/feminae/DetailsPage.aspx?Feminae_ID=28764 (25.09.2018)

Bizans İmparatorluğu'nda, sosyal yapılanmada yer alan ve bu anlamda idame ettirilen hayat içerisinde belli bir önem elde eden hadımların, ne çeşit bir tıbbi müdahaleden geçtiğiyle alakalı açık ve net bilgilere ulaşmak pek mümkün olmamıştır. Asilzadelerin ya da saray erkanının hizmetine verilen kısırlaştırılmış erillerin hayatlarının dönüm noktasını oluşturan bu müdahalenin ayrıntıları, en geniş haliyle Paulus Aegineta, adlı bir doktorun VII. yüzyılda derlemiş olduğu bir tıp ansiklopedisinde karşımıza çıkmıştır (Aegineta- Adams 1844-1847). Paulus Aegineta'nın vermiş olduğu bilgilere göre; Bizans'ta hadım etme işlemi, iki yöntem takip edilerek gerçekleştirilmiştir. Bu yöntemlerden ilki baskı yoluyla erkeklik organlarının ezilmesi ikincisi ise cinsel organın tamamen kesilerek vücuttan ayrılması şeklinde tanımlanmıştır (9) (Kimmel, Milrod \& Kennedy 2014, 33).

Tıbbi anlamda teknik bilgilerin nispeten yetersiz olduğu dönemde her türlü risk göze alınarak müdahale edilen ve böylelikle eril güçleri elinden alınan erkeklerin, Bizans İmparatorluğu Dönemi'nde kendi görev sahaları içerisinde farklı pozisyonlarda çalıştığı görülmüştür. Kişiler, vali ile veznedarlık gibi iki seçkin görevin dışında Parakoimomenos (baş hadım), Protovestiaros (imparatorun gardırobu ile ilgilenen hadım), İmparator Masası Sorumlusu, İmparatoriçe Masası Sorumlusu, Büyük Saray'ın Papias'1/kapıcısı(güvenlikle ilgilenen hadım), Magnaura (büyükelçilerin ağırlandığı salon) Salonu'nun Papias'1/kapıcısı (güvenlikle ilgilenen hadım), Daphne Sarayı'nın Papias'1/kapıcısı güvenlikle ilgilenen hadım), Büyük Saray'ın Deuteros'u (güvenlikle ilgilenen hadımın yardımcıs1), İmparator Pingernes'i/garsonu, Augusta Pingernes'i/garsonu gibi önemli işlerin başına getirilmiştir (Tougher 2008, 58). 
Bizans Dönemi'nde, bazı kıstaslar temel alınarak farklı işlerde görevlendirilen hadımların, devletin uzun süren hâkimiyet süreci içinde özelde yaptıkları işle alakalı değişik isimlerle çağrıldığı görülmüştür. Buna göre; hizmet sınıfında çalışan insanların yaptıkları iş ve sahip oldukları rütbeye göre iki ana başlık altında toplandığı tespit edilmiştir. Bunlardan ilk sınıfı IV. yüzyılın sonlarından itibaren ortaya çıkan ve Praepositus'un başkanlığında çalışan imparator ya da imparatoriçenin gardırobu, yemeği, mahzeni ve yatak odasıly ilgilenen "cubicularii" yani "kutsal yatak bekçileri" sıfatıyla saray içinde çalışan hadımlar grubu oluşturmuştur. İkinci sınıfı ise VI. yüzyıldan sonra ortadan kalkan "castrensis sacri palatii" (kâhya gibi) başkanlığında çalışan hadımlar grubunun oluşturduğu görülmüştür (Bury 1911, 121). Yapılan bu sınıflandırmaya ve elde edilen bilgilere göre ilk grupta yer alan hadımlar "parakoimomenos" başkanlığında "praepositus" olarak adlandırılan bir üst rütbenin emrinde çalışmıştır. Birinci çalışma grubu içine dâhil olan bu hadımlar; "comites sacrae vestis" (giyim kuşam işleriyle uğraşan hadımlar), "comites domorum" (yatakhanenin gelir giderlerini düzenleyen hadımlar) sıfatıyla saray içinde görev almıştır. Bu görevlere daha çok genç yaştaki hadımlar getirilmiştir. "Primicerius sacri cubiculi" (k1demli hadım) ile "praepositus sacri cubiculi" (yatakhaneden sorumlu en büyük hadım) başkanlığında çalışan "castrensis" (kâhya gibi); bu rütbenin emri altında "spatharius" (güvenlikten sorumlu hadımları yöneten kişi) ve "sacellarius" (özel giderleri yöneten kişi) gibi sıfatlarla çalışan hadımların, yukarıda adı geçen hadım görevlilere nazaran daha üst rütbede bulundukları görülmüştür. Sarayda parakoimomenos ile castrensis sacri palatii rütbesiyle görev alan ve bu rütbelerin altında çalışan hadımlar dışında farklı konum ve mevkilerde çalışan hadımların da var olduğu bilgisine erişilmiştir. Baş kâhyanın emri altında çalışan iki tane "tabularii" (imparator ve imparatoriçenin özel giderlerini düzenlemekle görevli hadımlar), bir tane "adiutor" (castrensis'e asiste etmekle görevli hadımlar) ve "chartularius" (kâtiplerle beraber sekreterlik işlerini yürütmekle görevli hadımların) saray içerisinde çalışan bir diğer hadım grubunu oluşturmuştur (Ciliers \& Retief 2004, 109).

Görev ve sorumluluklarıyla farklı çalışan gruplarını örnekleyen, saray içi teşkilatlanmada çalışan sınıf için bir düzen yaratan hiyerarşik sistemin, Bizans İmparatorluğu'nda IV. yüzyıldan itibaren takip edildiği söylenebilmiştir. Yüzyıllar arasında kadrolarda ve çalışanların alt ve üst rütbelerinde çeşitli değişiklikler olsa da erken dönemde kurulan ve hizmet sınıfı için işlerlik sağlayan bu düzenlemenin, sahada kaydedilecek ilerlemede temel alındığı tespit edilmiştir.

Bizans saraylarında, hiyerarşik sıralamada belli nitelikler gözetilse de zaman içerisinde birtakım rütbeler, bir adım daha öne geçmiştir. Bu kadroların "parakoimomenos" (imparatora en yakın hadım görevlidir; elinde silahı imparatorun kapısının önünde yatar ve efendisinin güvenliğini sağlar) ile imparatorun gardırobundan sorumlu "provestiaros"'lara ait olduğu bilgisine erişilmiştir. Rütbe olarak diğer çalışanlardan ayrılan bu iki görevli grubunun elde ettiği mevki sadece sıralamada yaratılan farkla tanımlanabilir hale getirilmemiştir. Yazılı kaynaklarda geçen kişilerin kazanmış olduğu mevkilerinin kıyafetleriyle de vurgulanır hale getirildiği bilgisi, bu anlamda değerli kabul edilmiştir (Hatzaki 2009, 96). Büyük resmi davetlere katılan, imparatorun mühründen sorumlu olan ve patris unvanını taşıyan, parakoimomenos'ların; üzeri zengin taşlarla süslü, altın renkli asa kullanmaları; imparatorun giyim kuşamından sorumlu olan ve imparatora ailesi dışında dokunabilme yetkisi taşıyan provestiaros 'ların ise geniş kollu yeşil manto giymeleri, bu kıyafetlerini taşlarla bezeli tokalı ayakkabılarla kombinlemeleri ve tıpk1 parakoimomenos'lar gibi ellerinde değerli taşlarla süslü asa taşımaları buna örnek gösterilebilmiştir (Marliave 2011, 131-132).

Saray içinde hizmette görevli olan ve kılık kıyafetlerindeki tasarımlarla kendi aralarında bir farklılık yaratan üst rütbeli hadımların sahip olduğu niteliklerinin benzer özelliklerle saray içerisinde çalışan diğer hadımlar tarafında da takip edildiği söylenebilmiştir. Üzerinde havuz 
betiminin işli olduğu keten bir gömlek giyen imparatorun yıkanmasıyla ilgilenen "nipsistarios" "lar, ellerinde kabzası altından bir kılıç taşıyan "spatharius/spatharokoubikoularios"lar, üzeri değerli taşlarla süslü, altın bir asa taşıyan "ostiarioslar" (kapıları tutan güvenlikten sorumlu olan hadımlar), kayısı rengi giysileri, omuzlarındaki ipekli bol pelerinleri ve gögüs hizasına imparatorun portresinin işlendiği gömlekleriyle tanınır hale gelen "saki” ler bu durumu örneklemiştir (Tougher 2008, 58).

Bizans saraylarında, bulundukları görevi temsil eden kıyafetler giyen hadımlar haricinde giyim kuşamda belli kriterler yaratan hadımların da varlı̆̆ dikkat çekmiştir. Nitekim genellikle beyaz tunik üzerine her yeri altın işlemelerle süslemiş kırmızı ceket giyen, nitelikli taşlarla bezeli gerdanlıklar takan ve çoğunlukla inciyle süslenmiş küpe takmayı tercih eden hadım çalışanların varlığı edindiğimiz bilgiler arasında yer almıştır (Westfahl 2015, 355).

Sosyal tarihçiler, hadımların çalıştıkları yerdeki görevleri, görevlerine istinaden taşımış oldukları unvanları, fiziksel özellikleri, kılık-kıyafetleri gibi onları tanımlamada belirli bir ölçüt yaratan nitelikleri, eski kaynakları temel alarak tüm detaylarıyla tanımlamış, bu kişilerin Bizans kültürü içindeki konum ve önemlerini sahada şeffaf bir bilgi birikimi yaratırcasına ele almıştır. Onlar tarafından yazın sahasında var edilen bu birikiminin ne yazık ki Bizans Dönemi sanat eserleri incelendiğinde ortaya konulan tasvirler üzerinden çok da yakalanamadığı tespit edilmiştir. Görevlerine ve taşımış oldukları unvana göre standart bir görüntü sunması gerektiği bilinen kişilerin ayırt edici ve fark yaratan görüntüler sunacak şekilde betimlenmemesi, kültür içinde belli bir konum ve görevde olan bu kişilerin, dönem sanatındaki yerinin belirlenmesinde önemli bir kriter yaratmıştır. Hükmeden ve hükmüyle hayatı yöneten imparatorların yanında yer alan, onların sadık kulu olarak hemen hemen onlar kadar sağlam bir güç edinen hadımların sahip olduğu şaşanın aksine sade bir görüntüyle betimlendiği en güzel örneklerden biri "parakoimomenos" ve "patrikios" sifatıyla özellikle IX. yüzyılda saray içinde etkin bir karakter olan hadım görevli Samonas'ın İmparator VI. Leo’yla tasvir edildiği minyatür (Fig. 4) vasıtasıyla karşımıza çıkmıştır. XII. yüzyıla tarihlendirilen bir el yazmasında yer alan bu minyatürde, Samonas altın renkli bir bordürle etek ucu süslenen açı mor renkli bir kıyafetle betimlenmiştir. Efendisinin önünde elleri göbek hizasında durur şekilde tasvir edilen Samonas'ın bu görüntüsü-özellikle kıyafetinin işlenişi- yazılı kaynaklarda bu unvandaki kişilerin sahip olduğu kıyafet biçimini yakalamadığı için önemli kabul edilebilmiştir. Aynı özellikteki bir başka örnek yine aynı yüzyıla tarihlenen bir el yazması üzerinden takip edilebilmiştir. İmparatoriçe Zoe'nin, Sgouritzes'ten John Orphanotrophos'u zehirlemesini istediği sahnede imparatoriçenin önünde bulunan, onun hizmetinde çalışan ve bir hadım olduğu düşünülen kişinin yine özelliksiz bir kıyafetle betimlenişi önem arz etmiştir (Fig. 5). İnce yapılı vücudu, sakalsız yüzü ile sevimli bir görüntü sunan figürün tasvirindeki tüm detayların, zihinlerde şekillenen biçimin aksine işaret eder şekliyle karşımıza çıkması, belli kriterlerin sanat sahasında yaratılmadığıyla alakalı ortaya koyduğumuz genellemenin adeta sınırlarının çizilmesini kolaylaştırmıştır.

Hadım oldukları konusunda bilgi sahibi olduğumuz hatta görev ve unvanlarıla ilgili çeşitli bilgilere erişebildiğimiz kişilerin tasvirlerindeki yalınlık dönem içerisinde takip edilen üslubun niteliklerini belli kalıplar dahilinde incelememizi olanaklı kılsa da dönem içinde genel bir şemanın takip edilmediğini ispat eden tasvirlerin varlığı, sanatsal yaratımın kendi içindeki değişkenliklerle değerlendirilmesini gerekli kılmıştır. Farklılık yaratan, kurgu ve işlenişiyle bahsini ettiğimiz yalın ifadeli betimlerden ayrı bir kategori yaratan en önemli örneklerden biri, San Vitale Kilisesi mozaiklerinde, İmparatoriçe Theodora'nın (Fig. 6) mahiyetiyle tasvir edildiği sahnede karşımıza çıkmıştır. Saray hayatına, dönemin giyim kuşam modasına dair pek 
çok ayrıntının yakalandığı sahnede, baş hadım ve onun yardımcısı olarak görev yapan hadımın, İmparatoriçe Theodora'nın sağında tasvir edildiği görülmüştür (Ringrose 2008, 76).

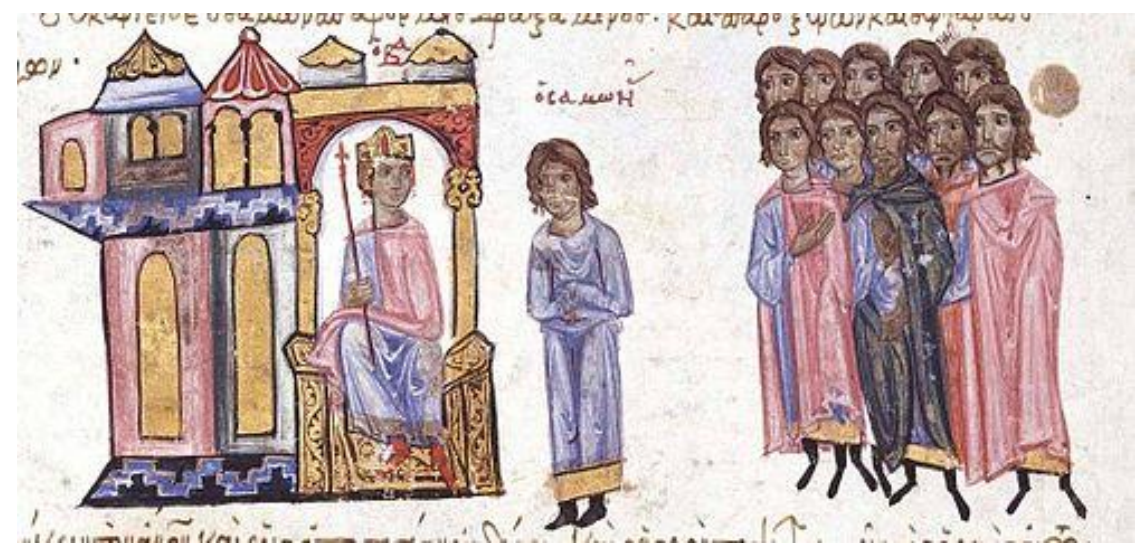

Fig. 4. Samonas İmparator VI. Leo’yu Andronikos Doukas'a karşı kışkırtmaktadır. XII. yüzyıl. Kaynak: Madrid Skylitzes, fol. 113r

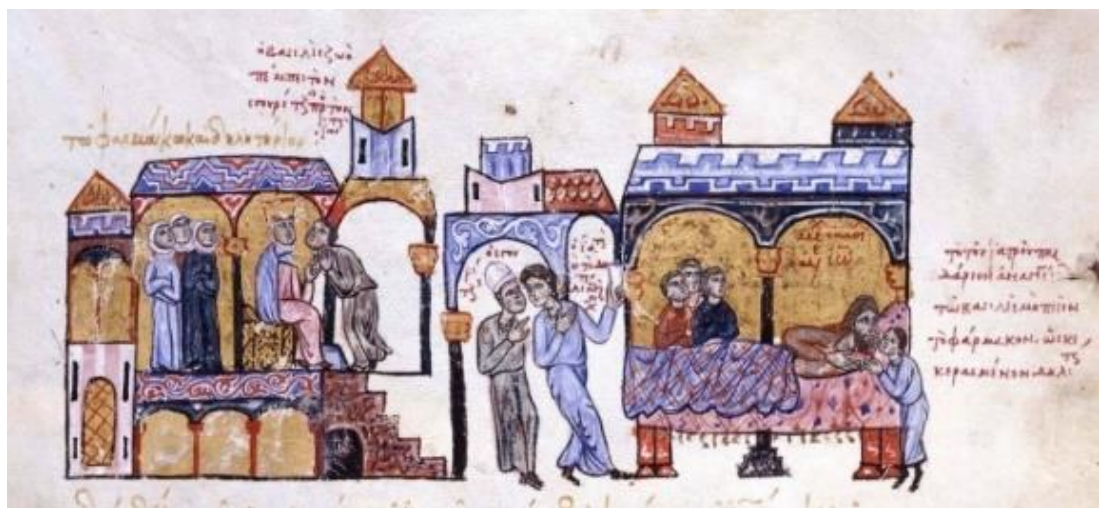

Fig. 5. İmparatoriçe Zoe, Sgouritzes'ten John Orphanotrophos'u Zehirlemesini İstiyor. XII. yüzyıl. Kaynak: Madrid Skylitzes, fol. 212r

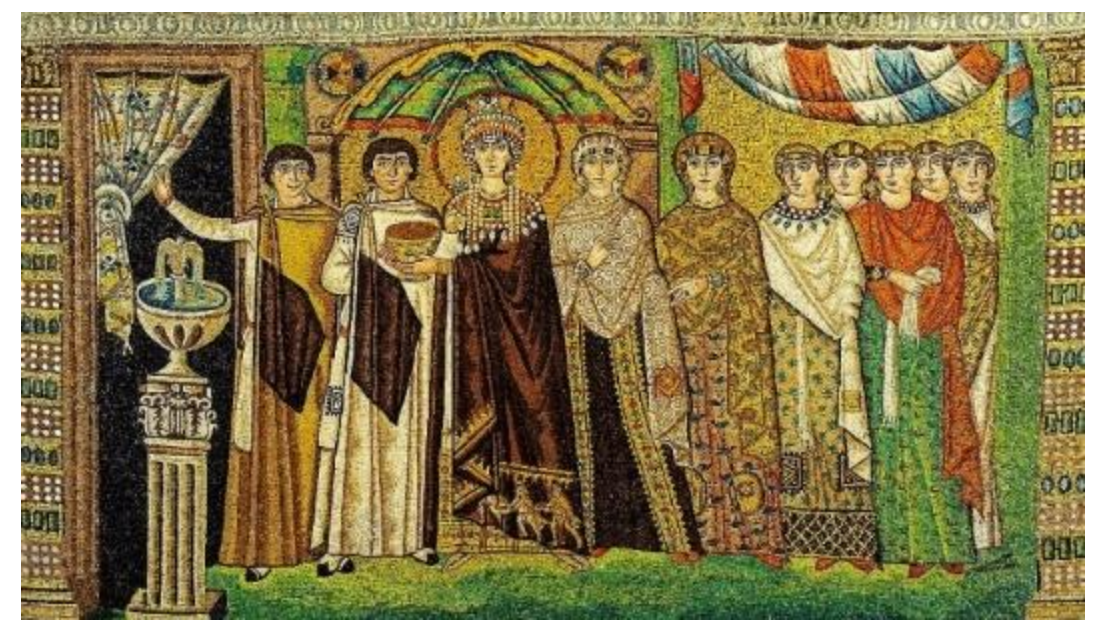

Fig. 6. İmparatoriçe Theodora ve Mahiyeti, San Vitale Kilisesi, Ravenna-İtalya VI. yüzy1l. Kaynak: (https://www.daummuseum.org/wp-content/uploads/2014/11/ravenna_Mosaic_of_Theodora__Basilica_San_Vitale.jpg (20.02.2020) 
İmparatoriçe Theodora'nın kadın hizmetliler ve emrinde görev yapan hadımlarla betimlendiği sahnede yer alan; uzun pelerinli, yakalarında büyük ve gösterişli broşlar bulunan, uzun, ince yapılı, narin yüz hatlarına sahip bu sakalsız erkek betimleri tam anlamıyla yazılı kaynaklarda unvanına göre kıyafet detayı değişen figürleri tanımlamamızı sağlamıştır. Hadımların yetki ve kıdemlerine göre sahip oldukları ihtişamı vurgulayan bu anlamda farklı bir kurguyla karşılaşılmasını sağlayan bir diğer örnek, "patrikios", "praepositos" ve "sakellarios" Leo'nun, Theotokos Meryem'e Kutsal Kitap İncil'i sunduğu sahne olmuştur. X. yüzyıla tarihlenen bir el yazmasında yer alan betimde Leo'nun, üzerinde kırmızı renkli bir kaftanla tasvir edildiği görülmüştür. Etek uçlarındaki altın renkli bordürle kıyafetinin görsel etkisi perçinlenen Leo'nun buradaki tasviri, onun konumunu vurgulayan tüm nitelikleri gözler önüne seren bir detay olarak değerlendirilebilmiştir (Fig. 7). Bahsettiğimiz bu iki örnekteki muhteşem detayların tekrarının yer aldığı benzer bir betim IX. yüzyıla tarihlenen bir minyatür vasıtasıyla karşımıza çıkmıştır. Eski Ahit'te adı geçen, manevi yetkinliğe, bir beşer olarak derin bir hissiyata sahip olan (Tevrat, Daniel: 512) ve bir hadım olduğu düşünülen Daniel'in (Ringrose 2004, 98) tasviri bu anlamda önem kazanmıştır. Figürün; saçlarının toplanış şekli, yapılan modele göre saçlara eklenen inci taşlar ve kıyafetin özellikle boyun kısmındaki inci dizisi ile betimlenişi, kişilerin sahip olduğu ihtişamı tasvirdeki detaylarla vurgulanan örneklere güzel bir temsil yaratmıştır (Fig. 8). Hadımların görsel sanatlarda yazılı kaynaklarda geçen gösterişli kıyafetleriyle betimlendiği son sahne yine bir minyatürde yer alan tasvirde karşımıza çıkmıştır. İmparator III. Nikephoros Botaneiates saray görevlileriyle birlikte betimlendiği sahnede, imparatorun sağında betimlenen hadımın görünüşü oldukça ilgi çekicidir. Sakalsız bu şekliyle parlak yüzlü bir görünüm sunan, ince vücut tipiyle fiziksel anlamda belli nitelikleri vurgular şekilde betimlenen, rengârenk kiyafetlerle postur olarak (elleri göbek hizasında bağlı durmaktadır) imparatora saygıda kusur göstermeyen bir namzet olarak betimlenen kişinin (Dumitrescu 1987, 38) yazılı kaynaklarda pek çok özelliğiyle tanımlanan Bizans Dönemi yüksek rütbeli hadımlarını tanımladığı söylenebilmiştir (Fig. 9).

Bizans İmparatorluğu Dönemi’nde saray içinde kalarak siyasi alanda belli bir güç kazanan hadımların aynı etkiyle dini yaşam içinde de etken rol oynadıkları görülmüştür. Manastırlarda ve dini kurumlarda görev alabilen dolayısıyla kilise hiyerarşisi içine girip bu konu da herhangi bir sınırlamayla karşılaşmadan piskopos, metropolit ve dahi patrik unvanına erişebilen hadımların varlığı, devlettin başka bir kol üzerinden yürüttüğü siyaset örneği olarak karşımıza çıkmıştır.

Bizans Dönemi'nde hadımların saray içerisindeki varlıkları ve onların kariyer anlamında üst rütbelerde bulunması insanların bu duruma daha 1lımlı yaklaşmasına ve hatta konuyu yakından takip etmelerine sebep olmuştur. Öyle ki makam sevdası X. yüzyılda ailelerin çocuklarını hadım etmelerine ve kiliseye göndermelerine yol açmıştır. Miletos piskoposu Nikephoros'un hadım edilmesi ve kiliseye gönderilmesi açıklamaya çalıştığımız bu duruma verilebilecek en önemli örneklerden birini oluşturmuştur (Ringrose 2004, 62). Dini yaşam içerisinde etkin bir isim olması için hadım edilen kişilerin dışında farklı amaçlara hizmetten hadım edilen kişilerin de varlı̆̆ı dikkatlerden kaçmamıştır. Siyasi emeller gözetilerek hadım edilen, hayatında tam anlamıyla bir kırılma noktası yaratılan böylelikle imparator olma şansı elinden alınan (Butler 1845, 469) fakat kilise hiyerarşisinde yükselerek Konstantinopolis'in patriği olma sıfatına erişen St. Ignatios'u bu durum ve konum için verilebilecek en önemli temsillerden biri olarak tanımlamak mümkün olmuştur (Fig.10).

Bizans döneminde dünyevi zevkleri tanrı için bırakan, şehvet ve arzu gibi insan nefsini kamçılayan duygulardan uzaklaşarak bedenen ve manen temizlenen hadımlar, taşımış oldukları masumiyet 
ve saflık gibi güzel hasletlerle meleklerle eş tutulmuştur. Aslında imparatorun tanrının yeryüzündeki gölgesi olarak düşünülmesi bu durumun altında yatan temel nedenlerden birini oluşturmuştur. Buna göre; halk için ve onların iyiliği için uğraşan imparator ilahi kudretin sembolü olarak görülmüş çevresinde bulunan, ona yakın olan kişiler de bu nispette kutsal sayılmıştır (Guiland 1943, 202). Dini ve ikonografik anlamda oluşan bu şema doğrudan sanat sahasını da etkilemiştir. Betimlenen melek figürleri ile hadımlara işaret edilebilmiştir (Fig. 11). Özellikle Başmelek Mikhail ve seraphim melekleri bu benzetme de ana karakterler olarak kullanılmıştır (Ringrose 2004, 125).

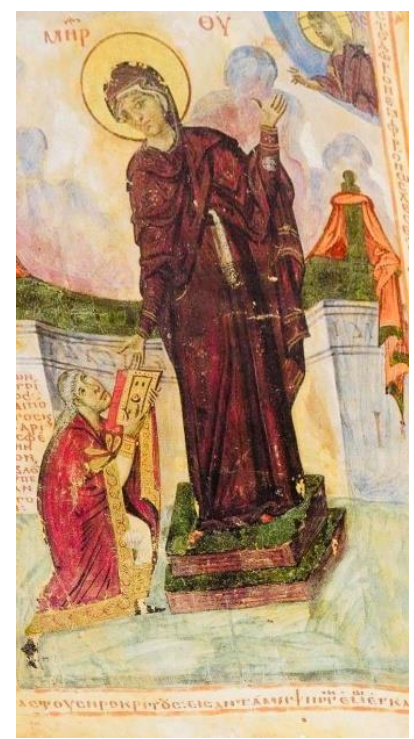

Fig. 7. Patrikios, Praepositos ve Sakellarios Leo'nun, Theotokos Meryem'e Kutsal Kitap İncil'i Sunması Sahnesi, X. yüzyıl.

Kaynak: Die Bibel des Patricius Leo: Codex Reginensis Graecus a B, ed. Suzy Dufrenne and Paul Canart (Zurich, 1988), fol. Zv)

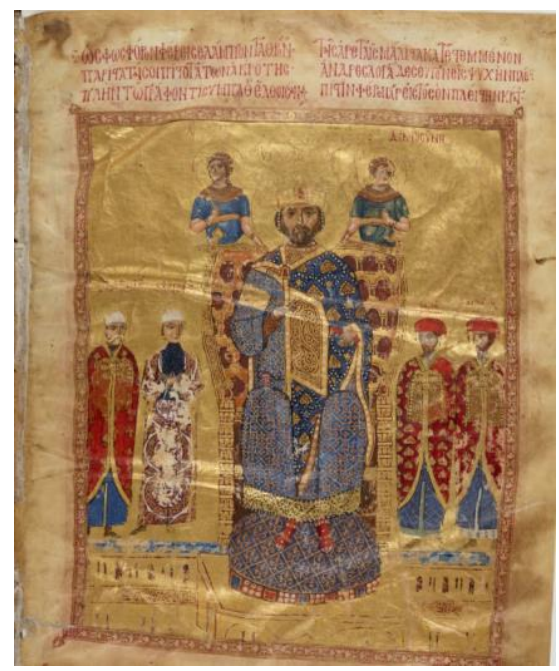

Fig. 9. İmparator III. Nikephoros Botaneiates Saray Görevlileriyle Birlikte Betimlendiği Sahne.

Kaynak: Paris, BN, Ms Coislin 79, fol. 2 r

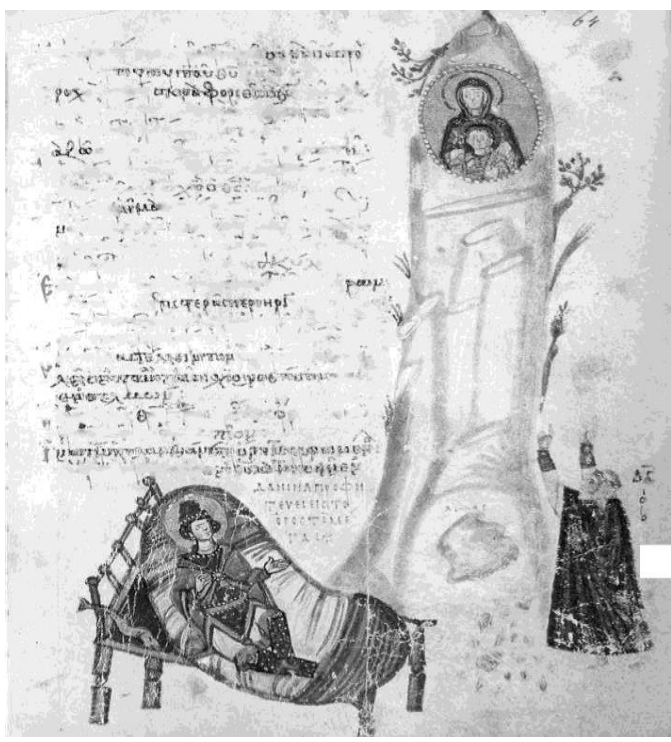

Fig. 8. Pers Saray Kiyafetleri ile Betimlenen Daniel, IX. yüzyıl.

Kaynak: Khludov Psalter, Historical Museum, Moscow, Ms 129 d, f. 64r

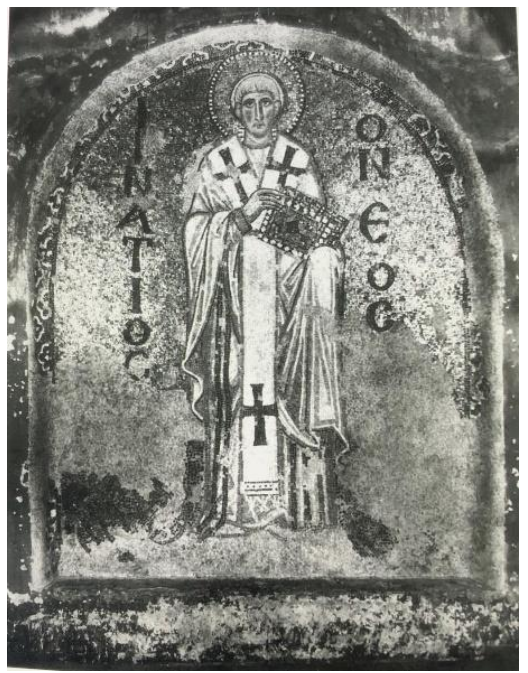

Fig. 10. Bizans İmparatoru I. Mikhail'in Konstantinopolis Patriği olan oğlu St. Ignatios, Ayasofya Kilisesi, Kuzey Tympanum Üzerindeki Mozaik, İstanbul.

Kaynak: Hawkins, ve Mango. 1972, s. 49, fig. 12 
Meleklerle eş kıymet ve değerde görülen hadımların, dini hayat içinde etkileri de bu denli yoğun olmuştur. Özellikle rahibe manastırlarında görev yapacak olan papazların hadımlar arasından seçilmesi hem güven duygusunun tatmin edilmesi hem de görevde hadımların muntazam bir iş anlayışıyla çalışacaklarına dair geliştirilen inançla sağlanmıştır. Bazı durumlarda hadımlar bir ceza yöntemi olarak manastırlara gönderilmiştir. Bizans görsel sanatlarında bu durumun işlendiği; açık olmasa da birtakım çıkarımlar yapılarak konun bu şekilde yorumlanmasını sağlayan görsellerin olduğu görülmüştür. Bahsetmeye çalıştığımız durumu örnekleyen en önemli görsel ise XI. yüzyıla ait bir minyatür vasıtasıyla günümüze taşınmıştır. Bizans İmparatoru III. Nikephoros'un Ioannes Krysostomos ve solunda Başmelek Mikhail ile betimlendiği sahne, bu sebeple bizler için büyük önem taşımıştır (Pentcheva 2006, 631-655). Sahnede imparatorun ayaklarının altında oldukça küçük ebatlarda işlenen ve kılık kıyafetindeki özenli detaylarla düzgün bir görünüm sergileyen figürün, hadım bir rahip (Tougher 2008, 113) olduğu düşünülmüştür (Fig. 12).

Bizans İmparatorluk Dönemi içinde hadımlar sadece özel alandaki hiyerarşik sıralamada yer alıp din ve siyaset üzerinde etkili olmamıştır. Dönem içinde yaşamış birçok hadımın aynı zamanda orduya komuta ederek askeri anlamda da birtakım başarılılar elde ettikleri görülmüştür. Hadımların devletin savunma mekanizması içine girip bu sistemde başrol oynamaları I. Iustinianos döneminden sonra yoğunluk kazanmıştır. Bu döneme kadar hadımların devletin dış güçlere karşı sağlam durmasını sağlayacak olan önemli birimi orduda yer almaması, tamamen bu kişilerin savaş anlamında barındırdıkları maharete ihtiyatla yaklaşmalarından kaynaklanmıştır. Bütün bunlara rağmen yine bu dönemde ordunun başına geçen hadımların varlığı gözden kaçmamıştır. I. Iustinianos döneminden sonra birçok örneğiyle karşılaşılan hadımların ordu başına geçmesi durumu Komnenos hanedanlığı döneminde tekrar durağan bir döneme girmiştir. Bu dönemde III. Nikephoros Botaneiates'in (1078-1081) protovestiaros'u Ioannes gibi birçok hadım yüzünden alınan yenilgi, bu duruma sebebiyet vermiştir (Tougher 2008, 120-121; Gaul 2002, 199-221).

Bizans Dönemi'nde konulan kural ve takınılan tavırla beraber bir görünüp bir kaybolan hadım generaller ya da orduya komuta eden üst düzey yöneticilerin, sanat sahasında da bu tavır etkili olmuş olacak ki betim açısından çok fazla örnekleriyle karşılaşılmamıştır. I. Iustinianos döneminin Pers asıllı devlet içinde ilk olarak "spatharius" ve "cubicularii" sıfatıyla görev yapan Narses adlı hizmetkârı, bu anlamda bir fark oluşturmuştur (Sidéris 2005, 248). San Vitale Kilisesi duvar mozaiklerinde imparatorun hemen solunda yer alan bu kişi, burada yer alan betimiyle günümüze kadar gelebilmeyi başarmıştır. Üst düzey yöneticilik anlamında Narses'in betimi askeri düzeydeki hadımların betimlenişi konusunda önem taşımışıı (Fig. 13).

Bizans İmparatorluğu'nda, devletin oluşumunu sağlayan, bu anlamda siyasi bir organizasyonun kurulmasında temel alınan çeşitli kurum ve kuruluşlarda yaptıkları görevler neticesiyle önemli yerlere gelen hadımların, özellikle başkent Konstantinopolis'te, saray hayatı içerisinde etkin rol oynadığ1 söylenebilmiştir. Deuterokanonik'lerde "Hiçbir suç işlemeyen hadım kişiyi de kutsayalım, çünkü o Rabbi'ne karşı herhangi bir günah tasarlamamıştır. Onda sevgi bağlılı̆̆ olduğu için Onunla özel olarak ilgilenilecek, Tanrı'nın Tapınağı'nda bir payı olacak" (Deuterokanonik Kitaplar, Bilgelik: 3-19) şeklinde geçen sözlerle inanç sistemindeki yeri ve önemi ile ilgili bilgiler edindiğimiz bu kişiler, hakimiyeti yüzlerce yıl süren imparatorluk tarihinde sahip oldukları tüm güçle beraber varlıklarını IV. yüzyıldan XII. yüzyıla taşıyabilmiştir. İmparator ve imparatoriçelerin sağ kolu olan, yöneten kesimle kurulan iletişim sayesinde en az hizmet ettikleri kişiler kadar kuvvet kazanan hadımların, bu geniş tarihsel süreç içerisinde sosyal ve kültürel hayata bıraktıkları izi, dönem sanatına da bıraktıkları söylenebilmiştir. 


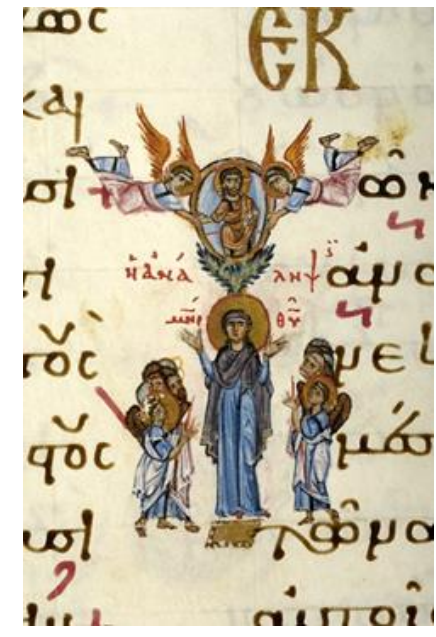

Fig. 11. İsa’nın Göğe Yükselişi, XI. yüzyıl sonu, İstanbul. Kaynak: Hamilton Lectionary Pierpont

Morgan Library, cod. MS 639, fol. 39r. http://ica.themorgan.org/manuscript/page/12/121467 (29.09.2018)

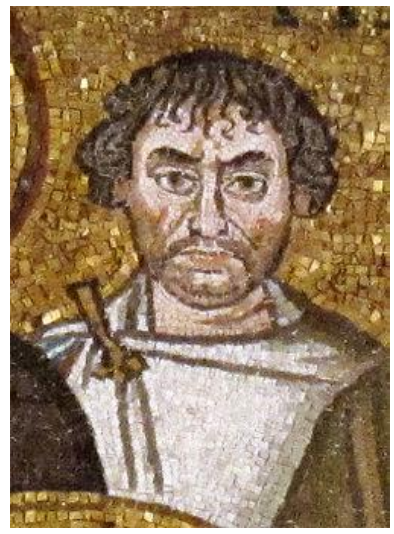

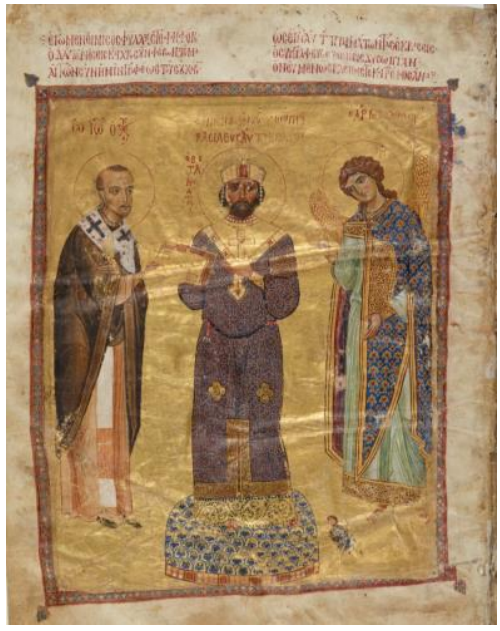

Fig. 12. Bizans İmparatoru III. Nikephoros, Sağında Ioannes Krysostomos;

Solunda Başmelek Mikhail ile betimlenmiştir.

Kaynak: Bibliotheque nationale de France.

Coislin 79, Folio 2v

Fig. 13. Narses, 532'de Nika isyanının bastırılmasına katkıda bulunmuştur. 538'de İtalya'da savaşan Belisarios'u desteklemek için gönderilen bir ordunun başına geçmiştir. Ergenlik sonrası hadım edildiği için tasvirlerde sakallı olarak betimlenmiştir. Kaynak:https://www.metmuseum.org/art/collection/ search/466586 20.02.2020)

Toplum nazarındaki yerleri ve sürdürülen hayat içerisindeki konumlar, doğal bir gelişim süreci olarak sanatçıların tasavvurlarını etkilemiş ve kişilerin yapılan tasvirleri üretilen ya da ortaya konulan her bir eserde gerçekçi bir suretle karşılaşılmasını sağlamıştır.

Bizans tasvir sanatında, bir dönemin sosyal ve kültürel hayatına damga vuran hadımların, sade ve yalın bir ifade kuracak şekilde tasvir edildiği görülmüştür. Yazılı kaynaklarda geçen ve kişilerin sahip olduğu ihtişama dair (kılık-kıyafet) önemli bilgiler veren çoğu detay, tasvirler üzerinde dikkat edilen bir kıstas yaratmamıştır. San Vitale Kilisesi’ndeki İmparatoriçe Theodora ve Mahiyeti'nin tasvirinde (Fig. 6), Pers Saray Kiyafetleri ile Betimlenen Daniel (Fig. 8) betiminde ve Patrikios, Praepositos ve Sakellarios Leo'nun, Theotokos Meryem'e Kutsal Kitap İncil'i Sunması Sahnesi'nde (Fig. 7) işlenen ve hadım oldukları doğrultusunda öngörü ve yorumlarda bulunduğumuz kişilerin tasvirleri, alan içinde bir farklılık yaratsa da bu durum kurulan yalın ifadenin kırılmasını sağlayamamıştır.

Bizans tasvir sanatında hizmet sektörünün önemli kişileri olan hadımların genellikle ince vücut tipleri (Fig. 2), renkli kıyafetleri (Fig. 4), postürleri (Fig.3) ve sakalsız, aydınlık yüzleriyle (Fig. 5-7-10) genel anlamda bir birlik yaratan figürler olarak eserler üzerinde tasvir edildiği söylenebilmiştir. Standart ve genel bir tasvir ediliş biçimini yansıtan, çoğunlukla mozaik, el yazması gibi küçük el sanatlarını örnekleyen eser grupları üzerinde yer alan tasvirler, kimi 
imparatoriçeleri kimi imparatorları vasıtasıyla günümüze göz kırpan hadımların tanınırlığını sağlamış fakat konuyla ilgili yeterli verilere ulaşılmasına ya da net tanımlamalar yapılmasına imkân yaratmamıştır. Dünyevi zevklerden arınmış, nefsin arzu ve heveslerinden uzaklaşmış, insan olma benliğinden uzaklaşarak manevi bir bütünlüğe kavuşmuş kimi zaman bir melek tasviriyle bütünleşerek hayatımıza dâhil olmuş kişilerin kültürel ve sosyal hayatta yüklenmiş oldukları misyon, ortaya konulan tasvirlerle tüm yönleriyle irdelenemeyen fakat var olduğu bilinen bir gerçeklik olarak günümüze kadar gelmeyi başarmıştır.

\section{Yazarın Notu}

Bu çalışma, Mimar Sinan Güzel Sanatlar Üniversitesi Edebiyat Fakültesi Sanat Tarihi Bölümü tarafından düzenlenen XXII. Uluslararası Ortaçağ ve Türk Dönemi Kazıları ve Sanat Tarihi Araştırmaları Sempozyumu'nda (24-26 Ekim 2018), "Bizans Imparatorluk Sisteminin İdeal Hizmetkârları: Hadımlar” başlığı adı altında sunulan tebliğin gözden geçirilmiş ve geliştirilmiş halidir.

\section{NOTLAR}

1- 2002 yılında Kuzey Yorkshire'da Catterick’te (İngiltere) yapılan kazılarda içinde kadın kıyafeti ve takılarıyla gömülmüş olan bir iskeletin olduğu mezar gün ışı̆̆ına çıkarılmıştır. Oldukça ilginç veriler sunan mezarın hadım edilmiş bir rahibe ait olabileceği düşünülmüştür. Buluntunun bereket tanrıçası Kibele kültüyle alakalı veriler sunabileceği bu yönde yapılan bir eşleştirmenin yanlış olmayacağ düşünülmüştür. Ayrıntılı bilgi için bkz. (Eckardt et al.2015, 191-223).

2- Örnek için bkz. (Harris, 2002).

3- Gerçek adı Carlo Maria Broschi olan, Farinelli ismiyle bilinen XVIII. yüzyılın ünlü İtalyan opera sanatçısının hayatının anlatıldığı 1994 yapımı film bu anlamda ilgi çekicidir. Gérard Corbiau'nun yönetmeliğini üstlendiği yakın tarihte yaşamış olan hadım sanatçının hayat hikâyesinin anlatıldığı film konu bakımından bizler için de büyük önem taşımıştır.

4- Yunan tarihçi Hellanicus/Helanikos'un hadımların ilk olarak Ahameniş İmparatorluğu (Pers Devleti) zamanında kraliçe Attosa (Hutaosâ) (Tuplin,1996:166) Romalı tarihçi yazar Ammianus Marcellinus'un ise hadımların ilk olarak Asur kraliçesi Semiramis (Sammuramat) (Tougher 1999, 58; Smith 2008, 199) dönemiyle birlikte tarih sahnesine çıktı̆̆ 1 şeklinde yapmış olduğu yorum, anlatmaya çalıştığımız durumu örneklemiştir.

5- Bazı araştırmacılar yine aynı dönem ve kültüre ait olan, üzerinde cinsiyetle ilgili herhangi bir tanımlama yapılamayan insan figürlerini (bu figürler Tanrıça İnanna/İştar (Innin/Inanna/Ishtar) kültüyle ilişkilendirilmiştir) hadımların varlığıyla özdeşleştirmiş̧; kimliği tespit edilemeyen bu kişilerin hadımlara, üçüncü cinsiyet grubuna işaret ettiğini söylemiştir. Ayrıntılı bilgi için bkz. Pollock \& Bernbeck 2000, 157, fig. 13.3).

6- Roma İmparatorluk Dönemi'nde hadımların ya da hadım edilecek kişilerin sınır bölgelerinden getirilmesinin en önemli sebebi Romalıların, soydaşları üzerinde bu tip bir müdahalede bulunmayı hoş görmemeleriyle açıklanabilmiştir. Öyle ki uygulamanın örneklerinin ortadan kaldırılması için Titus Flavius Domitianus (Domitian), Marcus Cocceius Nerva (Nerva) ve Publius Aelius Traianus Hadrianus (Hadrian) (Charles, Anagnostou-Laoutides, 2010, 186; Guiland, 1943, 198) gibi devlet tarihine yön veren büyük imparatorlar döneminde, uygulamayı yapan kişilere ağır cezalar verildiği bilgisine erişilmiştir. Aslında devlet tarafından alınan bu yasal önlemler, sadece uygulamanın birey hakları üzerindeki olumsuz etkisi düşünülerek alınmamıştır. Hadımların toplumsal yaşamda asayişi bozabileceği ihtimali de yasal birtakım kuralların konulmasını gerekli kılmıştır. Alınan tedbirlerle erkeksi özellikler kazanmamış vücutlarla yakın temasta bulunmayı şevkle isteyen ve hamile kalma riski olmadığı için bu tip bir ilişki yaşamaktan geri durmayacak olan kadınların, bu kadınların ihtiyaçlarına cevap veren eril güçleri elinden alınan erkeklerin, toplumsal yaşam için taşıdığı tehlike de bertaraf edilmek istenmiştir (Stevenson 1995, 499; Wassersug, R. 2006, 3169; Barbier 1996).

7- Kurulan devasa köle pazarlarında 10 yaş altındaki köleler 30, 10 yaş üzerindeki köleler 50, sağlanan yaş kriteri ile birlikle yetenekli olduğuna inanılan köleler 60 solidiyeye satılmıştır. Ayrıntılı bilgi için bkz. The Code of Justinian Book VII, Title 7.

8- Danelis isimli bu kadının, IX. yüzyılın sonunda, dönemin imparatoru I. Basileios'a yaklaşık yüz adet hadım köle hediye etmesi günümüze ulaşan bilgiler arasında yer almaktadır (Rautman 2006, 28; Cavallo 1997, 5).

9- Birinci yöntem genellikle çocuk yaşta hadım edilecek bireyler üzerinde uygulanmıştır. Hadım edilecek çocuklar ilk olarak sıcak su havuzlarında bekletilmiş, vücutlarının sıcak su etkisi ile yumuşaması beklenmiş, dokular yumuşadıktan sonra testisler parmakla ezilerek hissiz hale getirilene kadar sıkıştırılmıştır. İkinci yöntem ise yaş almış bireylerde uygulanmıştır. Kişi düz bir zemin üzerine sırt üstü yatırılmış, her iki testisine derin bir bıçak darbesi indirilerek organın vücuttan ayrılması sağlanmıştır. Çoğu ölümle sonuçlanan bu tekniğe (Guiland 1943, 199) birinci teknikle karşılaştırıldığında çok daha fazla başvurulduğu görülmüştür. Baskı yöntemiyle yapılan kastrasyonlarda kişinin cinsel istek duyabileceği ihtimalinin olması ikinci yöntemde ise bunun tamamen ortadan kaldırıldığı bilgisi, insanları tehlikeli de olsa bu tekniği kullanmaya teşvik etmiştir (Tougher 1997, 175). 


\section{BIBBLIYOGRAFYA}

Barbier P. 1996, The World of the Castrati: The History of an Extraordinary Operatic Phenomenon. London.

Bury J. B. 1911, The Imperial Administrative System in the Ninth Century, with a Revised Text of Kletorologion of Philotheos. London

Butler A. 1845, The Lives of the Fathers, Martyrs and Other Principal Saints X. Dublin.

Casperson J. W. 2007, Toward Spiritual Sovereignty: A Secular Bible. USA.

Cavallo G. 1997, The Byzantines. USA.

Charles M. B. \& Anagnostou-Laoutides E. 2010, “The Sexual Hypocrisy of Domitian: Suet. Dom. 8, 3”. L'Antiquité Classique 79, 173-187.

Ciliers L. \& Retief F. P. 2004, "The Eunuchs of Early Byzantium”. Scholia: Studies in Classical Antiquity 13, 108-117.

Defranza M. K. 2015, Sex Difference in Christian Theology: Male, Female, and Intersex in the Image of God. UK 2015.

Dumitrescu C. L. 1987, "Remarques en Marge du "Coislin 79": Les Trois Eunuques et le Problème du Donateur". Byzantion 57/1, 32-45.

Eckardt H., Müldner G. \& G. Speed 2015, "The Late Roman Field Army in Northern Britain? Mobility, Material Culture and Multi-Isotope Analysis at Scorton (N Yorks)". Britannia 46, 191-223.

Forcellini E. 1858, Totius Latinitatis Lexicon: Opera Et Studio Aegidii Forcellini Lucubratum. Warszawa.

Gaul N. 2002, "Eunuchs in the Late Byzantine Empire, c. 1250-1400”. Ed. Shaun Tougher. Eunuchs in Antiquity and Beyond, 199-221.

Guiland R. 1943, "Les Eunuques dans l'Empire Byzantin: Étude de Titulature et de Prosopographie Byzantines". Revue Des Études Byzantines I, 197-238.

Harris C. 2002, Memoirs of a Byzantine Eunuch. İstanbul.

Hathaway J. 2012, Beshir Agha: Chief Eunuch of the Ottoman Imperial Harem. UK.

Hatzaki M. 2009, Beauty and the Male Body in Byzantium: Perceptions and Representations in Art and Text. UK.

Hawkins E. J. W. \& Mango C. 1972, “The Mosaics of St. Sophia at Istanbul: The Church Fathers in the North Tympanum". Dumbarton Oaks Papers 26, 4-84.

Herrin J. 2009, Byzantium: The Suprising of a Medieval Empire. Oxford.

Herrin J. 2010, Bizans: Bir Ortaçă̆ Imparatorluğu'nun Şaşırtıcı Yaşamı/Byzantium: The Suprising of a Medieval Empire. Çev. Uygur Kocabaşoğlu. İstanbul.

Jones A. H. M. 1986, The Later Roman Empire, 284-602: A Social Economic and Administrative Surve II. UK 1986.

Kimmel M., C. Milrod \& A. Kennedy (2014), Cultural Encyclopedia of the Penis. London 2014.

Laneri N. 2002, "The Discovery of a Funerary Ritual: Inanna/Ishtar and Her Descent to the Nether World in Titriş Höyük, Turkey". East and West 52, 1/4, 9-51.

Marliave de O. 2011, Hadımların Dünyası-Çă̆lar Boyu Hadımlık. Çev. Yasemin Kayacan. İstanbul.

Paulus A. \& Francis A. 1844-1847, The Seven Books of Paulus Agineta. Publications of the Sydenham Society. London.

Peace A. \& Anderson J. 2012, All About Sex... In The Bible. USA.

Pentcheva B. 2006, “The Performative Icon”. The Art Bulletin 88/4, 631-655.

Rautman M. L. 2006, Daily Life in the Byzantine Empire. London.

Reusch K. 2016, "Reading Between the Lines: Disparate Data and Castration Studies". Eds. M. L. Mant \& A. J. Holland. Beyond the Bones: Engaging with Disparate Datasets, 61-80. New York.

Ringrose K. 2004, The Perfect Servant: Eunuchs and the Social Construction of Gender in Byzantium. London.

Ringrose K. 2008, "Women and Power at Byzantine Court". Ed. Anne Walthall. Servants of the Dynasty: Palace Women in World History, 65-80. USA.

Sidéris G. 2005, "Une Société de Ville Capitale: Les Eunuques dans la Constantinople Byzantine (IVeXIIe siècle)". Actes des Congrès de la Société des Historiens Médiévistes de L'enseignement Supérieur Public, 36 Congrès: Les villes capitales au Moyen Age, 243-274.

Smith B. G. 2008, The Oxford Encyclopedia of Women in World History II. USA.

Stevenson W. 1995, "The Rise of Eunuchs in Greco-Roman Antiquity". Journal of the History of Sexuality 5/4, 495-511. 
Taneri A. 1997, "Hadım". TDV İslam Ansiklopedisi. C. 15, 1-3.

Taylor T. 2000, Castration: An Abbreviated History of Western Manhood. New York.

Tougher S. F. 1997, "Eunuchs: An Overview, With Special Reference to Their Creation and Origin”. Ed. Liz James. Women, Men, and Eunuchs: Gender in Byzantium, 168-184.

Tougher S. F. 1999, “Ammianus and the Eunuch”. Eds. Jan Willes Drijvers \& David Hunt. The Late Roman World and Its Historian: Interpreting Ammianus Marcellinus, 64-73.

Tougher S. F. 2008, The Eunuchs in Byzantine History and Society. New York.

Tougher, S. F. 2013, “Eunuch”. Ed. Nigel Wilson. Encyclopedia of Ancient Greece, 280-281.

Tuplin C. 1996, Achaemenid Studies. Stuttgard.

Tylor G. 2000, Castration: An Abbreviated History of Western Manhood. London.

Wassersug R. 2006, "The Sexuality and Social Performance of Androgen-Deprived (Castrated) Men Throughout History: Implications for Modern Day Cancer Patients. Social Science \& Medicine". Social Science \& Medicine 63, 3162-3173.

Wassersug R. J., E. Mckenna \& T. Lieberman 2012, "Eunuch As a Gender Identity After Castration". Journal of Gender Studies 21/3, 253-270.

Westfahl G. 2015, A Day in a Working Life: 300 Trades and Professions Through History. USA.

\section{Elektronik Kaynaklar}

http://www.tdk.gov.tr/index.php?option=com_gts\&kelime=HADIM (07.09.2018).

http://epistle.us/hbarticles/eunuchs2.html (08.08.2018).

https://inpress.lib.uiowa.edu/feminae/DetailsPage.aspx?Feminae_ID=28764 (25.09.2018).

https://www.metmuseum.org/art/collection/search/466586 20.02.2020).

https://www.daummuseum.org/wp-content/uploads/2014/11/ravenna_Mosaic_of_Theodora_-

_Basilica_San_Vitale.jpg (20.02.2020).

http://ica.themorgan.org/manuscript/page/12/121467 (29.09.2018).

http://bdh-rd.bne.es/viewer.vm?pid=d-1754254 (29.09.2018).

Tevrat:

https://www.kutsal-kitap.net/bible/tr/index.php?mc=3\&sc=1302\&id=1305 (12.07.2020).

Deuterokanonik Kitaplar

https://www.kutsal-kitap.net/bible/tr/index.php?mc=3\&sc=1302\&id=1305(12.07.2020). 